\title{
Comparison of the effect between two doses of vaginal misoprostol in the termination of first- trimester pregnancy: a double-blinded randomized trial
}

\begin{abstract}
Background and aim: a higher dose of misoprostol may increase its efficacy on the termination of pregnancy, we compared the impact of $400 \mu \mathrm{g}$ every 6 hours daily with $800 \mu \mathrm{g}$ daily of vaginal misoprostol for termination of early pregnancy.

Methods and materials: in this randomized clinical trial 90 pregnant women with gestational age less than 96 days were randomized to receive vaginal misoprostol either the $400 \mu \mathrm{g}$ every 6 hours (group A) or $800 \mu \mathrm{g}$ once a day (group B) for three days, then, success of abortion and complication of these methods were compared with each others.

Results: Of 90 recruited women, successful medical abortions occurred in 44 patients, 27 $(60 \%)$ women in group A and $17(37 \%)$ women in group B. The difference of success was significant $(\mathrm{P}=0.043)$. The severity of vaginal bleeding was significantly lower in group $\mathrm{A}(\mathrm{p}=0.004)$, but diarrhea and fever were more common in group A. No other serious complications such as massive hemorrhage were found in both groups.
\end{abstract}

Conclusion: lower but multiple doses of vaginal misoprostol (400 mcg every 6hrs) was more effective than $800 \mathrm{mcg}$ daily in the medical termination of first-trimester pregnancy.
Volume 9 Issue I - 2018

\author{
Farah Farzaneh, Donya khosravi, Maryam \\ Sadat Hosseini, Sara Defaei, Azadeh Fazel \\ Preventative Gynecology Research Center, Shahid Beheshti \\ University of Medical Sciences, Iran
}

Correspondence: Donya khosravi, Preventative Gynecology Research Center (PGRC), Imam Hossein Medical Center, Shahid Beheshti University of Medical Sciences, Tehran, Iran, Tel 982177543634, Fax 98-2177543634,

Email dr.khosravi.d@gmail.com

Received: August 19,2017 | Published: February 27, 2018

Keywords: pregnancy trimester, first - misoprostol - abortion

\section{Introduction}

The management of pregnancy termination by induced abortion is a prevalent obstetrics and gynecologic operation, however, it is invasive and in some cases risky procedure. ${ }^{1,2}$ Therefore, some specialists have presented medical abortion as an alternative for surgical abortion especially in mothers with early gestational age less than 7 weeks. ${ }^{3}$ Mifepristone was the first agent used for medical termination of pregnancy ${ }^{4}$ and some years later methotrexate was approved for medical abortion. ${ }^{5}$ Prostaglandin agents are the most common drugs, to achieve the medical termination in women in the first and second trimester of pregnancy. ${ }^{4}$ Misoprostol is a synthetic analog of prostaglandin E1 that firstly was approved by the Food and Drug Administration (FDA) for peptic ulcer ${ }^{4}$ and later it has been administered in patients with unwilling pregnancy to induce abortion. ${ }^{5,6}$ Bugalho et al. ${ }^{7}$ administered vaginal misoprostol for medical abortion and demonstrated that it was effective agent to terminate the pregnancy and the successful rate was about $80 \%,{ }^{7}$ furthermore, these results repeated in some other trials used misoprostol and revealed it is high efficient agent with low serious side effects in women under medical abortion..$^{8-12}$ To increase the efficacy of misoprostol, it has been used in combination with other agents such as methotrexate and mifepristone for the termination of pregnancy in the first trimester and reported a highly efficacy ranged from $83-97 \% \cdot{ }^{13,14}$ On the other hand, recent experiences proved that women are more satisfied with medical abortion using misoprostol. In this regard, a study by Zikopoulos revealed that $91.3 \%$ of the women are satisfied with medical termination and they were very keen to choose it again and recommended it to other women. ${ }^{15}$ Some other practices confirmed more efficacies with higher doses of misoprostol. ${ }^{16-20}$ Therefore, in this randomized double-blinded clinical trial we compared the efficacy of two doses of vaginal misoprostol for elective termination of pregnancies in women with gestational age less than 96 days.

\section{Materials and methods}

The study was prospectively conducted at Imam Hussein University Hospital between 2013 and 2014. The research has been approved by the ethic committee of Shahid Beheshti University of Medical Sciences, Tehran, Iran (registration number sbmu. rec.1393.553). Our plan is comparison of the effect between two doses of vaginal misoprostol in the termination of first-trimester pregnancy. The criteria for enrollment were singleton pregnancy, indication for pregnancy termination due to either fetal or maternal causes or gestational age $\leq 96$ days (e.g, missed abortion, blighted ovum, and maternal medical problem). The exclusion criteria were any sign or symptom of threatened or spontaneous abortion before therapy such as bleeding, any degree of dilatation in cervix or uterine regular contractions before drug administration, evidence of septic abortion, serum hemoglobin level $<10 \mathrm{~g} / \mathrm{dl}$, coagulopathy disorders, cardiovascular or cerebrovascular diseases, uterine leiomyoma and allergy to the misoprostol. The study procedure was explained to the patients and informed written consent was obtained. A demographic questioner was filled then pelvic examination and the gestational age was calculated and 90 women with gestational age less than 96 days were recruited and randomized into two groups. To randomization we used sequential numbers, in this case the first number was given to the first patient and received misoprostol $400 \mu$ g every 6 hours up to three days (group $\mathrm{A}, \mathrm{n}=45$ ) sequentially the next number was given to next patient and received misoprostol $800 \mu \mathrm{g}$ daily plus three doses of placebo every 6 hours for three days (group B, n=45). Both groups and study staff (site investigators and trial coordinating center staff) 
were masked to treatment allocation. During the treatment period (3 days) any side effects such as diarrhea, fever (tempreture $\geq 38$ ), chills, nausea and vomiting and vaginal discharge were recorded in a chart in both groups, moreover, two groups visited regularly and the level of hemoglobin and amount of vaginal bleeding such as spotting, less than menses, equal to menses and more than menses were measured. Successful abortion was defined as complete passage of the pregnancy with no need for curettage, complete passage of tissue and transvaginal ultrasound was done for them and confirmed by ultrasonography. If the presence of remnants of gestational sac in ultrasound was less than $20 \mathrm{~mm}$, it was complete abortion (within 72 hours after the initiation of misoprostol). Failure was defined as a need for surgical dilatation and curettage (D\&C) due to the presence of remnants of gestational sac in ultrasound (more than $20 \mathrm{~mm}$ ), abnormal bleeding or prolonged vaginal bleeding because of incomplete abortion or no response to treatments after 72 hours. For each unsuccessful abortion, two separate gynecologists independently evaluated the conditions and confirmed the failure to decide on the surgical intervention. If needed, D\&C was done by manual vacuum aspiration after taking written informed consent.

\section{Statistical analyses}

The data were analyzed using Statistical Package for Social Studies version 22.0 (SPSS Inc, Chicago, Ill). Categorical data are presented as numbers (\%), and continuous data as mean $\pm \mathrm{SD}$. We used the Chai_2 or to compare categorical variables and the Student's t test to compare continuous variables. $\mathrm{P}<0.05$ was considered significant.

\section{Results}

90 pregnant women mean age $28.75 \pm 5.95$ and mean gestational age $11.25 \pm 1.85$ weeks were evaluated (Table 1 ). The number of patients with successful abortion in group A was significantly more than B ( 27 patients in group A versus 17 patients in group $\mathrm{B}, \mathrm{P}=0.043$ ). The failure of the misoprostol treat was significantly lower in group A. The women who did not respond to misoprostol in both groups were divided in three categories (all ended with $\mathrm{D} \& \mathrm{C}$ ): first with ongoing pregnancy, second with incomplete abortion, third with persistent bleeding after misoprostol. These categories were, also compared in both groups. The failure of the misoprostol treat in the ongoing pregnancy was significantly lower in group A. (2 patients in group $A$ versus 5 patients in group $\mathrm{B}, \mathrm{P}=0.004)$. The number of incomplete uterine passage of gestational tissue with remain product of conception which was another indication of $\mathrm{D} \& \mathrm{C}$ was non-significantly more in group $\mathrm{B}$ ( 12 versus $14, \mathrm{P}=0.76)$. Persistent bleeding occurred in 4 patients in group $\mathrm{A}$ and 9 in group $\mathrm{B},(\mathrm{P}=0.001), \mathrm{D} \& \mathrm{C}$ was performed in this patients (Table 2). Anaphylaxis after administration of the first dose of misoprostol was not observed in both groups. The frequency of fever and diarrhea in group A was significantly higher than group B $(\mathrm{P}=0.009)$. No, severe complications including transfusion, emergent surgery for hemorrhage, or sepsis occurred in both groups (Table $3)$. Regarding bleeding, the spotting was nonsignificantly more in group $\mathrm{A}$ than $\mathrm{B}$, but bleeding less, equal and more than mense was significantly more in group B than A (Table 3).

Table I The patients' characteristics

\begin{tabular}{|c|c|c|c|}
\hline Group & $\begin{array}{l}\text { Group A ( }(n=45) \text { misoprostol } \\
1600 \text { miq/day) }\end{array}$ & $\begin{array}{l}\text { Group } A B(n=45) \text { misoprostol } 800 \\
\text { miq/daily }\end{array}$ & $\mathbf{P}$ \\
\hline Age(year ) & $28.42 \pm 5.132$ & $29.22 \pm 6.675$ & 0.887 \\
\hline Gestational age(week) & $8.78 \pm 1.664$ & $10.27 \pm 2.016$ & 0.001 \\
\hline BMI & $24.46 \pm 2.74$ & $25.00 \pm 3.14$ & 0.319 \\
\hline Total drugs dose $(\mu \mathrm{g})$ & $1208.89 \pm 5 \mid 5.144$ & $|506.76 \pm 6| 4.432$ & 0.001 \\
\hline Volume of remaining sac in vaginal sonography & $18.56 \pm \mid 2.0632$ & $26.40 \pm 19.088$ & 0.003 \\
\hline Pain score during treatment(VAS) & $5.222 \pm 2.678$ & $4.467 \pm 2.582$ & 0.074 \\
\hline Missed abortion & $42.2 \%(19)$ & $46.7 \%(2 I)$ & 0.067 \\
\hline Blighted abortion & $33.3 \%(15)$ & $35.6 \%(16$ & 0.043 \\
\hline Maternal abortion & $8.9 \%(4)$ & $8.9 \%(4)$ & 0.124 \\
\hline Induced Abortion & $15.6 \%(7)$ & $8.9 \%(4)$ & 0.095 \\
\hline Transvaginal sonography(volume of residual remnants of fetus) gr & $18.56 \pm 12.0632$ & $26.40 \pm 19.088$ & 0.003 \\
\hline Curettage (\%) & $40 \%(18)$ & 64.4. \%(29) & 0.002 \\
\hline Closed cervix (\%) & $91.1 \%(4 I)$ & $77.8 \%(35)$ & 0.375 \\
\hline
\end{tabular}

Table 2 The frequency of successful abortion rate

\begin{tabular}{llll}
\hline Groups & Group A (n=45) misoprostol $\mathbf{1 6 0 0 ~ m i q / d a y )}$ & Group AB(n=45) misoprostol 800 miq/daily & P \\
\hline complete abortion & $27(60.0 \%)$ & $17(37.8 \%)$ & 0.043 \\
No respond to misoprostol (D\&C) & $2(4.4 \%)$ & $5(11.1 \%)$ & 0.004 \\
Incomplete uterine passage (D\&C) & $12(26.7 \%)$ & $14(31.1 \%)$ & 0.765 \\
persistent bleeding (D\&C) & $4(8.9 \%)$ & $9(20.0)$ & 0.001 \\
\hline
\end{tabular}

Table 3 The frequency of side effects of medical abortion in two groups

\begin{tabular}{lllll}
\hline & & Group A (n=45) misoprostol $\mathbf{1 6 0 0}$ miq/day) & Group AB(n=45) misoprostol 800 miq/daily P \\
\hline Bleeding & spotting & $20(44.4 \%)$ & $17(37.8 \%)$ & 0.087 \\
& Less than mense & $7(15.6 \%)$ & $10(22.1 \%)$ & 0.004 \\
& Equal to mense & $3(6.7 \%)$ & $4(8.9 \%)$ & 0.034 \\
& More than mense & $5(1.1 \%)$ & $11(2.2 \%)$ & 0.044 \\
fever & & $10(22.2 \%)$ & $3(6.7 \%)$ & 0.001 \\
diarrhea & $2(4.4 \%)$ & $1(2.2 \%)$ & 0.905 \\
Vaginal discharge & & $33(73.3 \%)$ & $35(77.8 \%)$ & 0.345 \\
Pain(VAS) & & $5.55 \pm 2.67$ & $4.46 \pm 2.58$ & 0.074 \\
No side effect & & $73.3 \%(33)$ & $77.8 \%(35)$ & 0.345 \\
\hline
\end{tabular}




\section{Discussion}

We compared the success rate and complications of medical abortion with two misoprostol doses $(400 \mu \mathrm{g} / 6$ houres and $800 \mu \mathrm{g}$ daily) for three days in women with gestational age lower than 96 days and revealed successful abortion in the half of the women (44 of 90), this rate in group under $400 \mu \mathrm{g} / 6$ hours $(1600 \mu \mathrm{g}$ daily) was significantly more than group treated with $800 \mu \mathrm{g}$ daily $(27$ versus $17, \mathrm{P}=0.001$ ), Furthermore, the severity of vaginal bleeding was significantly lower in group $\mathrm{A}(\mathrm{p}=0.004)$. In agreement with these findings, a study in Mashhad in 2008 by Ayati et al. ${ }^{17}$ on 100 women was performed to evaluate the effect of misoprostol role in the termination of pregnancy in the first trimester. They administered $800 \mu \mathrm{g}$ vaginal misoprostol for initiation and $800 \mu \mathrm{g}$ after 24 hours if the abortion was not successful. They reported a significant difference between abortion rate after administration of first $(800 \mu \mathrm{g})$ and second dose $(1600 \mu \mathrm{g})$ of misoprostol ( $55 \%$ vs $83 \%)$. However, the successful rate was more than our practice $(83 \%$ vs $49 \%)$ and failure rate was $17 \%$ (needed curettage) (17). A similar study in methodology to our work by Zikopoulos, evaluated the role of the vaginal misoprostol ( $800 \mu \mathrm{g}$ daily) in 160 women with $<42$ and $<56$ days of gestational age and repeated every 24 hours for three days. They revealed the abortion rate about $96 \%$ and $86 \%$, respectively, moreover the study indicated that the complete termination was significantly different after the 1 st and 2 nd dose ( 71.3 vs $92.5 \%$ in group A, 51.3 vs $80 \%$ in group B). Harmoniously, 47 of 90 patients in our trial needed curettage in the group treated with misoprostol $800 \mu \mathrm{g}$ daily that was remarkably higher than Zikopoulos practice with only two patients, needing curettage (15). Another study by Grapsas et al. ${ }^{18}$ reported higher complete abortion rate than our practice. The authors administered single vaginal misoprostol $(800 \mu \mathrm{g} /$ day) to the 113 women in the first trimester (up to 12 weeks of gestational age) and revealed $74 \%$ complete abortion on the first day( $37 \%$ in our study in group treated with $800 \mu$ g daily), the authors confirmed that the gestational age was not correlated with the abortion rate. ${ }^{18}$ In line with these studies, a review by Faúndes et al.${ }^{19}$ in 2007 reported $85-90 \%$ complete abortion in patients with a gestational age of 12 weeks under misoprostol $800 \mu \mathrm{g}$ first dose and additional doses at 6,12 and 24 hours later. Moreover, this review indicated more acceptances among the patients with oral and sublingual routes and more efficacies with the vaginal route of administration. ${ }^{19}$ These results were supported by further studies including a study by Singh et al. ${ }^{20}$ with $800 \mu \mathrm{g}$ of vaginal misoprostol and 3 doses with three hours' interval and a success rate about $96 \%$. In keeping with our findings, this study emphasized that the rate of complete termination in patients under repeated dose was more than a single dose. ${ }^{20}$ In 2005 a trial by Sifakis et al. ${ }^{21}$ administered a high dose of vaginal misoprostol $(400-3600 \mu \mathrm{g})$ in three days, $400 \mu \mathrm{g}$ for initiation and $400 \mu \mathrm{g}$ every 4 hours and reported $68.5 \%$ complete abortion in first day $(2400 \mu \mathrm{g} /$ day) and more than $90 \%$ successful rate after $3600 \mu \mathrm{g}$ maximum dose. $^{21}$ The reasons for such discrepancy between our results and these studies regarding the successful abortion rate may be due to the route of misoprostol administration, the studies indicated a wide range of the complete abortion rate from $25 \%$ in oral administration to $97 \%$ for vaginal route in some studies, ${ }^{22}$ in this case a study by Kutlu et al. ${ }^{23}$ combined the routes of administration, they initiated with misoprostol vaginal and continued with oral administration (1200 $\mu$ total dose) and achieved $95 \%$ of complete abortion. ${ }^{23}$ In addition to the route of the administration, the misoprostol dose, the definition of success rate, exclusion, and inclusion criteria, and different of the methodology are another possible factors. For instance, the patients' selection and exclusion criteria in our study were basically different from Zikopoulos et al. ${ }^{15}$ study, because Zikopoulos excluded women with prior elective abortion and parity more than three, but we only excluded patients with prior infected abortion. ${ }^{15}$ Only one study by Shuaib et al. ${ }^{24}$ in 2013 administered a similar dose of misoprostol $(1600 \mu \mathrm{g} /$ day $)$ to our study and showed lower successful rate than our experience. The study compared the success rate and complications of medical abortion by $400 \mu \mathrm{g}$ misoprostol for induction and $200 \mu \mathrm{g}$ every 4 hours with the surgical abortion and showed $21 \%$ success rate after 12 hours $(1000 \mu \mathrm{g})$ and $57 \%$ success rate after 24 hours $(1600 \mu \mathrm{g})$ of treatment ${ }^{24}$ that was lower than our results in group treated with $1600 \mu \mathrm{g}$ daily with $60 \%$ success rate.

We did not find any study comparing different doses of vaginal misoprostol regimens in the first trimester of pregnancy, however, a randomized controlled trial by Pongsatha et al. ${ }^{25}$ compared the vaginal misoprostol loading and non-loading dose regimens and revealed that a loading dose of misoprostol was significantly related to higher rates of adverse effects and comparable success rate, they concluded that loading dose of misoprostol is not more effective than non-loading dose to induce abortion in second trimester, ${ }^{25}$ that was in contrast to all studies, evaluating the misoprostol effect, on the first trimester of pregnancy.

The main limitations of our study were the relatively small sample size and short duration of follow-up. Further investigations are recommended with longer follow- up and larger series to validate the findings reported here

Conclusion: lower but multiple doses of vaginal misoprostol ( $400 \mu \mathrm{g} / 6$ hours) were more effective with lower serious bleeding than higher single dose $(800 \mu \mathrm{g}$ daily) in the medical termination of pregnancy in the first trimester.

\section{Acknowledgements}

None.

\section{Conflicts of interest}

Authors declare there is no conflict of interest in publishing the article.

\section{References}

1. Coughlin LB, Roberts D, Haddad NG, et al. Medical management of first trimester miscarriage (blighted ovum and missed abortion): is it effective? J Obstet Gynaecol. 2004;24(1):69-77.

2. Harris LH, Dalton VK, Johnson TR. Surgical management of early pregnancy failure: history, politics, and safe cost-effective care. Am J Obstet Gynecol. 2007;196(5):445e1-445e5.

3. Shankar M, Economides DL, Sabin CA, et al. Outpatient medical management of missed miscarriage using misoprostol. Obstet Gynaecol. 2007;27(3):283-286.

4. Norman JE, Thong KJ, Baird DT. Uterine contractility and induction of abortion in early pregnancy by misoprostol and mifepristone. Lancet.1991;338(8777):1233-1236.

5. Barbosa RM, Arilha M. The Brazilian experience with Cytotec. Stud Fam Plann. 1993;24(4):236-240.

6. Coêlho HL, Teixeira AC, Santos AP, et al. Misoprostol and illegal abortion in Fortalezza, Brazil. Lancet. 1993;341(8855):1261-1263.

7. Bugalho A, Mocumbi S, Faúndes A, et al. Termination of pregnancies of $\leq 6$ weeks gestation with a single dose of 800 microg of vaginal misoprostol. Contraception. 2000;61(1):47-50. 
8. Carbonell JL, Varela L, Velazco A, et al. The use of misoprostol for abortion of 9 weeks gestation. Eur J Contracept Reprod Health Care. 1997;2(3):81-185.

9. Carbonell JL, Valera L, Velazco A, et al. Vaginal misoprostol for early second-trimester abortion. Eur J Contracept Reprod Health Care. 1998;3(2):93-98.

10. Carbonell JL, Varela L, Velazco A, et al. Vaginal misoprostol for abortion at 10-13 weeks' gestation. Eur J Contracept Reprod Health Care. 1999;4(1):1-6.

11. Carbonell JL, Varela L, Velazco A, et al. Vaginal misoprostol $1000 \mu \mathrm{g}$ for early abortion. Contraception. 2001;63(3):131-136.

12. Blanchard K, Winikoff B, Ellertson C. Misoprostol used alone for the termination of pregnancy. A review of the evidence. Contraception. 1999;59(4):209-217.

13. Borgatta L, Burnhill MS, Tyson J, et al. Early medical abortion with methotrexate and misoprostol. Obstet Gynecol. 2001;97(1):11-16.

14. Creinin MD, Schwartz JL, Pymar HC, et al. Efficacy of mifepristone followed on the same day by misoprostol for early termination of pregnancy: report of a randomized trial. $\mathrm{Br} J$ Obstet Gynaecol. 2001;108(5):469-473.

15. Zikopoulos KA, Papanikolaou EG, Kalantaridou SN, et al. Early pregnancy termination with vaginal misoprostol before and after 42 days gestation. Hum Reprod. 2002;17(12):3079-3083.

16. American College of Obstetricians and Gynecologists Practice Bulletin. Medical management of abortion. Obstet Gynecol. 2001;26:97.
17. Ayati S, Roudsari FV, Khadem N, et al. Medical abortion at first trimester of pregnancy with misoprostol. Saudi Med J. 2008;29(12):1739-42.

18. Grapsas X, Liberis V, Vassaras G, et al. Misoprostol and first trimester pregnancy termination. Clin Exp Obstet Gynecol. 2008;35(1):32-4.

19. Faúndes A, Fiala C, Tang OS, et al. Misoprostol for the termination of pregnancy up to 12 completed weeks of pregnancy. Int J Gynaecol Obstet. 2007;99 Suppl 2:S172-7.

20. Singh K, Fong YF, Dong F. A viable alternative to surgical vacuum aspiration: repeated doses of intravaginal misoprostol over 9 hours for medical termination of pregnancies up to eight weeks. BJOG. 2003;110(2):175-80.

21. Sifakis S, Angelakis E, Vardaki E, et al. High-dose misoprostol used in outpatient management of first trimester spontaneous abortion. Arch Gynecol Obstet. 2005;272(3):183-6.

22. Chen BA, Crenin MD. Medical management of early pregnancy failure: efficacy. Semin Reprod Med. 2008;26(5):411-23.

23. Kutlu T, Tuğrul S, Aran T, et al. Combined administration of misoprostol in the first and second trimester missed abortion cases. Clin Exp Obstet Gynecol. 2006;33(4):226-8.

24. Shuaib AA, Alharazi AH. Medical versus surgical termination of the first trimester missed miscarriage. Alexandria J Med. 2013;49(1):13-16.

25. Pongsatha S, Tongsong T. Randomized controlled trial comparing efficacy between a vaginal misoprostol loading and non-loading dose regimen for second-trimester pregnancy termination. J Obstet Gynaecol Res. 2014;40(1):155-60. 